\title{
An Associational Research on Turkish Children's Environmentally Responsible Behaviors, Nature Relatedness, and Motive Concerns
}

\author{
Fatma Bahar, Elvan Sahin* \\ Middle est Technical University \\ *Corresponding Author: selvan@metu.edu.tr
}

\section{ABSTRACT}

Science education has changed in recent decades with respect to key issues faced in this century. These issues such as renewable energy, waste management, air quality, and biodiversity require dealing with the transition toward a sustainable future. Thus, to contribute to the reconceptualization of science education in a developing country, the present study aimed to assess (1) Turkish middle school students' environmentally responsible behaviors, nature relatedness (NR), and motive concerns and (2) the power of environmental motive concerns, and NR in predicting the related behaviors. Measuring tools covering the NR scale, the environmental motive concerns, and children's responsible environmental behavior scale were administered to middle school students in the Northern part of Turkey. The results indicated that these students reflected an external nature-related worldview. Regarding their behaviors, it was revealed that the students frequently engaged in some actions linked to physical and economic contribution to the environmental quality. However, they did not demonstrate any actions on political commitment although they were very concerned about the environmental issues. Examining the predictors of their responsible environmental behaviors, a linear combination of these attributes significantly contributed to explaining such behaviors. This study provided practical tips for science and sustainability educators in that children could be provided with some opportunities to get in touch with nature and appreciate the value of being in nature.

KEY WORDS: environmentally responsible behaviors; nature relatedness; motive concerns; middle school students

\section{INTRODUCTION}

W

e as human beings are now suffering due to various problems that also affect non-human living things, and these problems are accelerating as we continue to undertake destructive actions. Climate change, deforestation, food insecurity, air pollution, etc., are among the threats facing our planet and require dealing with as we transition toward a sustainable future. Parallel with these trends; science education has changed in recent decades with respect to these threats. It has been proposed that through science education, individuals are expected to make critical judgments about science and increase their engagement to work for a more socially just, equitable and sustainable world (Carter, 2012). As pointed out by organizational declarations and educational researchers (e.g., Carter, 2012; U.S. Environmental Protection Agency, 2012), building up knowledge, skills and values through science enable us to make transitions to more sustainability. In line with this perspective, Education for Sustainability could be integrated into science education so that young people might be encouraged and equipped with necessary understanding, skills, and values to maintain their community.

Our connection with the natural environment has been depicted as a precursor to grasp the various aspects of sustainability (Orr, 2004; Higgns and Kirk, 2006). More specifically, Orr (2004) stated that as we try to enhance our awareness of personal and societal interaction with nature, we will better understand ecological, social and esthetic values of the environment. Maller et al. (2005) also indicated that people with little or no connection with nature do not feel a part of it and are not likely to value or show concern for the natural environment. From another standpoint, it was pointed out that as individuals realize the significance of their connection to nature and understands it better, and then they have more empathy for all living creatures (Feral, 1998). Consequently, Nisbet and Zelenski (2013) have recently directed researchers' attention toward an environmental, psychological construct called "nature relatedness" (NR) reflecting a human_NR. Specifically, these authors (Nisbet et al., 2009; Nisbet and Zelenski, 2013) claimed that NR lets us capture individual differences in how people view their connectedness with the natural world. Furthermore, they reported that possessing high NR or a strong subjective connection with nature leads to greater happiness and environmental concern. On the other hand, a disconnection with nature may yield adverse consequences in terms of both human and environmental health. Thus, research on sustainable living and education for sustainability has a focus on NR due to its potential to provide important implications.

In another study, Barthelmess et al. (2013) made a comparative survey study with South Korean, Swiss, and Czech students 
to assess their NR and ecological consciousness. 829 South Korean undergraduate students, 673 Swiss students and 147 Czech students participated. In this study, the researchers tried to answer the questions "Do the students from 3 different national settings share a similar scale of NR?" "If there are differences, in which way do they differ?" In other words, the aim of the study was to test the "NR scale" by comparing nations to see whether the scale could be applied in different nations and to what extent the differences in people's culture affect one's relationship with the natural world. The researchers found out that when investigating one's personal sense of closeness to nature, there was an East-West cultural variation. According to results, South Koreans felt closer to nature when compared to their Swiss and Czech counterparts. The researchers noted that for a high percentage of people living in cities they reported less familiarity with the natural environment. This study also suggested that well-educated young people revealed a clear individual sense of closeness toward nature.

At this point, it seems a plausible assumption to note that such kinds of individuals may also disclose the meaning of natural environment for them, show feelings of concern to protect nature, behave more responsibly toward it, and contribute to creating a sustainable future. However, research had indicated that although people held a certain degree of concern about the threats to nature, they do not always engage in environmentally responsible actions (Kaplan, 2000; Schultz, 2000).

Considering the complexities of human behaviors, Stern and Dietz (1994) brought conceptualization of environmental motive concerns forward and provided significant information about the nature of environmentally responsible behaviors. These authors claimed that a person may hold feelings of concern about adverse consequences of environmental challenges for valued objects which are oriented around self, for other people, or for the whole biosphere. These spheres of concern were designated as egoistic (concern for the self), social altruistic (concern for other people), and biospheric (concern for all living things) motive concerns (Stern and Dietz, 1994). In this context, examination of personal motive concerns and their association with various environmentrelated constructs has become a focus point for researchers and educators for many years (e.g., Dietz et al., 2002; Nordlund and Garvill, 2002; and Steg et al., 2005). Considering the degree of motive concerns that a person may hold, Milfont et al. (2006) conducted a cross-cultural study among university students and found that Asian New Zealanders had significantly higher egoistic concerns than European New Zealanders, while they possessed significantly lower biospheric concerns than European New Zealanders. On the other hand, a survey study (Onur et al., 2012) carried out with elementary students in Turkey demonstrated that the children's motive concerns were "not mutually exclusive" and they held these motive concerns to a similar degree. These claims were noted as being consistent with Stern and Dietz's (1994) arguments. Regarding the contribution of motive concerns in explaining pro-environmental behaviors, previous research studies (e.g., Milfont et al., 2006; Schultz et al., 2004) emphasized that biospheric concerns appeared to be consistently positively associated with pro-environmental behavior. However, the pattern of correlations for both egoistic and altruistic concerns was not consistent (Sahin, 2016; Schmuck, 2003).

Considering the patterns on the degree of holding connectedness to nature and motive concerns as well as the strength of relationships between the three environmental motive concerns, and NR with environmentally responsible behaviors, this study intended to clarify these inconsistencies for Turkish middle school students to highlight implications for middle school science education. In this aspect, the present study aimed (1) to determine middle school students' NR, motive concerns, and environmentally responsible behaviors and (2) to examine the power of NR, motive concerns in predicting these behaviors.

\section{METHODOLOGY}

\section{Sample}

Participants of this study were $17747^{\text {th }}$ and $8^{\text {th }}$ grade middle school students from a city center located in the Black Sea Region of Turkey. Among them, 859 students were $7^{\text {th }}$ graders (48.4\%), 802 students were $8^{\text {th }}$ graders $(45.2 \%)$, and 113 students $(6.4 \%)$ did not indicate their grade level. Regarding the gender distribution, 820 students $(46.2 \%)$ were female while 824 students (46.4\%) were male and 130 students (7.4\%) did not answer this question. The range of age distribution for that sample was $12-15$ years with a mean of 13.41 (standard deviation $[\mathrm{SD}]=0.651$ ).

\section{Instruments}

\section{Environmental motive concern scale}

The environmental motive concern scale developed by Schultz (2001) was previously adapted into Turkish by Onur et al. (2012) to assess the importance of valued objects centralized around the self, other people and the biosphere in terms of environmental risks. This 12 -item scale consists of three factors: egoistic (me, my lifestyle, my health, and my future), altruistic (people in my country, all people, future generations, and my children), and biospheric (plants, animals, birds, and marine life) motive concerns. The middle school students reflected their concern levels for the related objects on a 7-point rating scale from "(1) of no importance" to "(7) of ultimate importance."

Validity is a concern for survey instruments. This scale yielded consistent results with the process followed for the previously Turkish adapted version of the scale. The items in this version loaded on three motive concern dimensions (altruistic, egoistic, and biospheric) which overlapped with the dimensions in the original scale. However, as referred to the study conducted by Onur et al. (2012), "My children" originally placed in altruistic motive concern was found to be the most prominent item in the dimension of egoistic motive concern as a reflection of 
the cultural characteristics of Turkish society. Regarding the reliability issue of the scale, the Cronbach's alpha coefficients were calculated as $0.87,0.82$, and 0.86 for biospheric, egoistic, and altruistic motive concerns, respectively. For the whole scale, the Cronbach's alpha was found to be 0.87 . These measures indicated acceptable internal consistency for the motive concern scale.

\section{NR scale}

The scale measuring the affective, cognitive, and physical connections of individuals with the natural environment was developed by Nisbet et al. (2009). The measuring tool covered 21 items in a 5-point Likert type scale, (1) strongly disagree; (2) disagree; (3) undecided; (4) agree; (5) strongly agree, and three factors categorized as NR_Self, NR_Perspective, and NR_Experience. The first factor, NR_Self refers an internalized identification like thoughts, feelings of individuals toward nature while NR_Perspective represents an external, nature related worldviews of subjective human actions and their effects on other living things such as plants and animals. The last factor, NR_Experience, reflects a physical familiarity with the natural world (Nisbet et al., 2009). The NR scale was adapted into Turkish by Cakir et al. (2015). The adapted version of the instrument contains a factor structure that overlaps with the factors in the original scale. Regarding the internal consistency, Cronbach's alpha coefficient of NR scale was calculated as 0.84 . In terms of three factors structure, Cronbach's alpha coefficient of NR_Self, NR_perspective, and NR_experience was found, respectively, as $0.88,0.75$, and 0.71 .

\section{Children's responsible environmental behavior scale (CREBS)}

In this study, CREBS developed by Erdoğan et al. (2012) was used to assess the students' responsible behaviors on the environment. CREBS includes 23 7-point scale items, which was designed as four subscales: Political action (six items), physical action (six items), consumer and economic action (five items), and individual and public persuasion (six items). Political action represents the environmental actions in which individuals seek for governmental and political means, and also persuade governmental agencies to take action to protect the environment. Physical action refers to environmental actions in which individuals involve directly in the natural world to prevent the environmental threats. Consumer action refers to environmental actions in which individuals use monetary support or financial pressure. On the other hand, persuasion action requires being active environmentally to encourage others to protect the environment. The participants of this study were asked to rate the items with respect to the number of times they engaged in the mentioned action in the past 2 years. Thus, the participants rated the items on a 7-point scale in which the alternatives ranged from 0 to 6 . Six points were assigned "6" to "more than five," "5" to "5 times," "4" to "4 times," "3" to "3 times" and " 2 " to "twice," " 1 " to "once," and " 0 " to "never."

The internal consistency of CREBS Political, CREBS Physical, CREBS Consumer, and CREB Persuasion constructs was found to be as $0.91,0.89,0.88$, and 0.83 , respectively, when assessed with Cronbach's alpha. This coefficient was calculated as 0.90 for the whole scale representing high internal consistency of the instrument (Field, 2005).

\section{Data Analysis}

To assess Turkish middle school students' motive concerns, NR, and environmentally responsible behaviors, the percentage of participant responses to the scale items, means, and standard deviations were calculated using descriptive statistics for the environment-related constructs. Furthermore, multiple linear regression analysis was conducted to determine the significant predictors of middle school students' environmentally responsible behaviors. In this context, a measure of adjusted $\mathrm{R}^{2}$ was reported to show the proportion of variance in the criterion variable that could be explained by the predictor variable. In addition, part correlations (semipartial correlations) designed to eliminate the effect of one variable on two other variables while assessing the correlation between these two variables were also noted. Thus, part correlations could be used to have an idea about the unique contribution of a predictor variable on the criterion variable. The significance level was set at 0.05 .

\section{Procedure}

This research study was conducted ethically following the protocols approved by Institutional Review Board (i.e., Research Centre for Applied Ethics). The second author contacted the administrators and teachers where the instruments were administered after obtaining permission from both the Institutional Review Board and the Ministry of National Education. The students were informed about the purpose of the study and the procedures for completing the survey. They were also told that their identity would be kept confidential and that the findings of the research would not affect their school grades. In addition, the students were asked to complete the measuring tool on their own. The survey took about $3 \mathrm{~min}$ for the students to finish it.

\section{FINDINGS}

\section{Middle School Students NR}

In this study, the middle school students were asked to reveal their level of agreement to a series of statements assessing NR. Table 1 presents the students' agreements, in percentages, as well as the mean and standard deviation for the NR scale. To draw some inferences in a more comprehensive manner, we preferred to collapse strongly agree and agree into one category and did the same for disagree and strongly disagree. The mean score on NR Self subscale was calculated as 3.77 on a scale of $1-5(\mathrm{SD}=1.07)$. More specifically, the majority of the students supported the statements such as "I am very aware of environmental issues" (83.2\%); "I think a lot about the suffering of animals" (81.8\%); "I always think about how my actions affect the environment" (74.3\%); "I am not separate from nature, but a part of nature" $(60.8 \%)$. The results of the descriptive analysis showed that the middle school students 


\begin{tabular}{|c|c|c|c|c|c|c|}
\hline Example items & St D & D & $\mathbf{U}$ & A & St A & Mean $\pm S D$ \\
\hline \multicolumn{7}{|l|}{ NR_Self } \\
\hline I am not separate from nature, but a part of nature & 6.1 & 9.1 & 24.0 & 33.1 & 27.7 & $3.67 \pm 1.15$ \\
\hline I always think about how my actions affect the environment & 4.7 & 4.4 & 16.6 & 38.2 & 36.1 & $3.96 \pm 1.07$ \\
\hline I am very aware of environmental issues & 4.7 & 4.0 & 8.1 & 34.8 & 48.4 & $4.18 \pm 1.06$ \\
\hline I think a lot about the suffering of animals & 8.9 & 3.7 & 5.6 & 20.5 & 61.3 & $4.21 \pm 1.25$ \\
\hline \multicolumn{7}{|l|}{ NR-Experience } \\
\hline My ideal vacation spot would be a remote, wilderness area & 9.4 & 15.9 & 31.1 & 23.3 & 20.3 & $3.29 \pm 1.22$ \\
\hline I enjoy being outdoors, even in unpleasant weather & 3.7 & 2.0 & 4.8 & 28.9 & 60.6 & $4.40 \pm 0.95$ \\
\hline I enjoy digging in the earth and getting dirt on my hands & 12.9 & 14.7 & 19.8 & 27.1 & 25.5 & $3.38 \pm 1.34$ \\
\hline I take notice of wildlife wherever I am & 4.5 & 11.2 & 27.0 & 34.8 & 22.5 & $3.60 \pm 1.08$ \\
\hline \multicolumn{7}{|l|}{ NR-Perspective } \\
\hline Conservation is unnecessary because nature is strong enough to recover from any human impact & 64.6 & 14.5 & 7.8 & 5.4 & 7.7 & $1.77 \pm 1.25$ \\
\hline Animals, birds, and plants have fewer rights than humans & 58.6 & 19.2 & 7.8 & 6.7 & 7.7 & $1.85 \pm 1.26$ \\
\hline Nothing I do will change problems in other places on the planet & 15.7 & 17.2 & 28.2 & 19.6 & 19.3 & $2.10 \pm 1.32$ \\
\hline The state of non-human species is an indicator of the future for humans & 5.2 & 7.0 & 28.1 & 27.4 & 32.3 & $3.75 \pm 1.13$ \\
\hline
\end{tabular}

NR: Nature relatedness, SD: Standard deviation

had moderately favorable feelings and thoughts about their personal connection to nature.

Considering the students' physical familiarity with the natural world, the participants' feelings and thoughts were divided when it came to deciding about being outdoors. In the following items such as "My ideal vacation spot would be a remote, wilderness area" (31.1\%), and "I take notice of wildlife wherever I am" (27\%), relatively large numbers of the students were undecided. On the other hand, these students reported that being outdoors $(89.5 \%)$, and digging in the earth $(52.6 \%)$ was enjoyable for them. The mean score on NR_Experience subscale was calculated as 3.67 on a scale of $1-5(\mathrm{SD}=1.15)$.

Regarding NR_Perspective dimension assessing an individual's external nature-related worldview, the mean score was reported as $2.14(\mathrm{SD}=1.26)$. At this point, it should be noted that due to negatively worded statements, mean scores and percentages closer to 1 on this dimension reflected favorable external naturerelated worldview. The majority of the students disagreed with the statements such as "Conservation is unnecessary because nature is strong enough to recover from any human impact" (79.1\%) and "Animals, birds, and plants have fewer rights than humans" (77.8\%). Relatively high percentage of the students was undecided about the statements "Nothing I do will change problems in other places on the planet" $(28.2 \%)$ and "The state of non-human species is an indicator of the future for humans" $(28.1 \%)$. It could be concluded that these students cannot imagine the consequences of human actions and their interaction with the natural environment. Thus, they were not sure about how they could change dignity of our planet.

\section{Middle School Students' Environmentally Responsible Behaviors}

The middle school students were asked to indicate how many times they engaged in the written statements over the past 2 years. The mean score of 2.06 on a 7-point rating scale $(\mathrm{SD}=1.10)$ reflected a low level of student engagement in environmentally responsible actions. Considering the different dimensions of the scale, the results showed that these students were not inclined to demonstrate political actions frequently $(\mathrm{M}=0.44 ; \mathrm{SD}=1.04)$. More specifically, the majority of the students reported that they had never visited their mayor to encourage him/her to take environmental protection measures $(87.8 \%)$. Similarly, they noted that they had never talked with government officials to enforce environmental laws or punish people who violate these laws $(85.0 \%)$. Parallel with their commitment to political actions; these students did not put an effort to convince others that a certain environmental action is favorable/positive $(\mathrm{M}=1.80 ; \mathrm{SD}=1.58)$. In other words, regarding persuasion actions, most of the students did not talk with the others to take any positive/favorable action with respect to environmental quality. To exemplify, half of the students declared that they had never talked with other people about what measures to be taken to protect and not harm the environment. With a similar pattern, relatively large percentage of the students never talked with family $(40.7 \%)$ or their friends $(41.4 \%)$ to persuade others to engage in proenvironmental measures.

On the other hand, it was seen that the students were more likely to engage in individual actions requiring a personal physical commitment to the environmental protection $(\mathrm{M}=4.00 ; \mathrm{SD}=1.61)$. For instance, the majority of the students threw recyclable materials such as paper, glass, and plastics into recycling bins $(71.5 \%)$, took some steps to conserve water $(62.2 \%)$ and avoided improper disposal of trash/garbage in their local environment (59.9\%).

\section{Middle School Students' Motive Concerns}

The students declared the importance they devoted to items organized around self, other people and all living things in terms of environmental concern. The frequency distributions of the students' responses on motive concerns are presented in Table 2. It can be seen that the majority of the middle school 


\begin{tabular}{|c|c|c|c|c|c|c|c|c|c|}
\hline \multirow[t]{2}{*}{ Items } & \multicolumn{5}{|c|}{ Of no importance } & \multicolumn{2}{|c|}{$\begin{array}{l}\text { Of ultimate } \\
\text { importance }\end{array}$} & \multirow[t]{2}{*}{ Mean \pm SD } & \multirow[t]{2}{*}{ Rank order } \\
\hline & 1 & 2 & 3 & 4 & 5 & 6 & 7 & & \\
\hline \multicolumn{10}{|l|}{ Egoistic } \\
\hline $\mathrm{Me}$ & 1.9 & 1.1 & 2.0 & 2.1 & 4.8 & 6.1 & 82.0 & $6.53 \pm 1.32$ & 4 \\
\hline My children & 2.2 & 0.3 & 0.9 & 1.4 & 2.0 & 4.4 & 88.8 & $6.70 \pm 1.21$ & 1 \\
\hline My health & 1.4 & 0.9 & 0.9 & 2.3 & 2.0 & 6.2 & 86.3 & $6.67 \pm 1.41$ & 3 \\
\hline My lifestyle & 2.9 & 0.6 & 1.6 & 4.7 & 9.4 & 12.3 & 68.4 & $6.28 \pm 1.15$ & 6 \\
\hline My future & 0.9 & 0.9 & 1.1 & 2.3 & 2.0 & 6.9 & 85.9 & $6.68 \pm 1.19$ & 2 \\
\hline \multicolumn{10}{|l|}{ Altruistic } \\
\hline All people & 3.2 & 1.5 & 3.0 & 4.8 & 9.6 & 14.6 & 63.3 & $6.13 \pm 1.51$ & 8 \\
\hline People in my country & 3.2 & 1.4 & 3.3 & 5.7 & 9.8 & 13.5 & 63.1 & $6.11 \pm 1.52$ & 9 \\
\hline Next generations & 3.9 & 2.2 & 2.3 & 4.3 & 6.6 & 13.1 & 67.7 & $6.17 \pm 1.60$ & 7 \\
\hline \multicolumn{10}{|l|}{ Biospheric } \\
\hline Plants & 3.0 & 1.4 & 4.1 & 10.0 & 12.7 & 11.3 & 57.6 & $5.92 \pm 1.62$ & 10 \\
\hline Marine life & 3.0 & 2.3 & 4.9 & 8.6 & 10.0 & 14.5 & 56.7 & $5.91 \pm 1.65$ & 11 \\
\hline Animals & 1.0 & 0.6 & 2.5 & 5.5 & 7.7 & 13.4 & 69.2 & $6.35 \pm 1.72$ & 5 \\
\hline Birds & 2.7 & 3.7 & 5.7 & 9.1 & 12.2 & 13.7 & 53.0 & $5.77 \pm 1.33$ & 12 \\
\hline
\end{tabular}

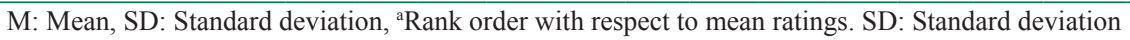

students attached importance to each item, but egoistic motive concerns appeared to be superior to altruistic and biospheric motive concerns. At this point, it should be also noted that "My children" (88.8\%) as an item originally placed in altruistic motives (Schultz, 2001) was rated as of ultimate importance even more frequently than the other egoistic motives such as "My health" (86.3\%), "My future," and "Me" (82.0\%). As illustrated in Table 3, parallel with the frequency distributions, the mean score calculated for the construct of egoistic motive concern $(\mathrm{M}=6.7, \mathrm{SD}=1.26)$ was higher than that of altruistic $(\mathrm{M}=6.14, \mathrm{SD}=1.54)$ and biospheric $(\mathrm{M}=5.99, \mathrm{SD}=1.58)$ motive concern. The corrected scores on egoistic, altruistic, and biospheric motive concerns were calculated (Table 3 ) as suggested by Schultz et al. (2004). The corrected mean scores were computed through calculating the average score of all items in the scale and subtracting the result from each of the three dimension scores.

\section{Predicting the Students' Environmentally Responsible Behaviors}

To determine significant predictors of middle school students' environmentally responsible behaviors, multiple regression analysis was conducted. It was revealed that the linear combination of biospheric and altruistic motive concerns as well as subdimensions of NR (NR_Self, NR_Perspective) was significantly related to such kind of behaviors $\left(\mathrm{R}^{2}=0.12\right.$, F $(4,1768)=26.81 . p<0.001)$. NR_Self was the significant predictor which explained the greatest proportion of the criterion variance uniquely $(\beta=0.22$; part correlation=0.20). The population value of $\beta$ (95\% confidence interval [CI]) for NR_Self Experience was found to be between 0.26 and 0.52 which exclude zero. Therefore, it was reasonable to conclude that NR_Self as a determinant of responsible environmental behaviors was statistically significant in terms of conventional

\begin{tabular}{lcc}
\hline Table 3: Mean ratings and SDs on motive concerns \\
\hline Dimensions of the scale & \multicolumn{2}{c}{ Mean \pm SD } \\
\cline { 2 - 3 } & Raw mean & Corrected mean \\
\hline Egoistic & $6.57 \pm 1.26$ & $0.34 \pm 0.78$ \\
Altruistic & $6.14 \pm 1.54$ & $-0.09 \pm 0.89$ \\
Biospheric & $5.99 \pm 1.58$ & $-0.24 \pm 0.88$ \\
\hline
\end{tabular}

SDs: Standard deviations

standards (Smithson, 2003). Furthermore, biospheric $(\beta=0.15$; part correlation $=0.12 ; 95 \% \mathrm{CI}: 0.06,0.18)$ and altruistic concerns $(\beta=0.12$; part correlation $=0.10 ; 95 \%$ CI: $0.04,0.16)$ significantly and positively contributed to the causal model while NR_Perspective $(\beta=-0.12$; part correlation $=-0.12 ; 95 \%$ CI: $-0.34,-0.10)$ significantly and negatively contributed. The results also showed that the combination of the predictors, namely, NR_Self, NR_Perspective, and biospheric and altruistic motive concerns explained a small portion of the variance, as displayed in Table $4,12 \%$ of the variance in responsible environmental behavior scores was explained by the predictor values. According to the results of the current study, NR_Experience and egoistic concerns of the students were not a significant predictor for responsible environmental behaviors.

\section{DISCUSSION}

Middle School Students' NR, Motive Concerns, and Environmentally Responsible Behaviors

The present study was an initial step to assess middle school students' connectedness with nature and motive concerns while also investigating the significant contribution of these constructs to predict environmentally responsible behaviors in Turkey. It was shown that these students moderately developed 


\begin{tabular}{|c|c|c|c|c|c|c|c|}
\hline Predictors & St. $\beta$ & Part-Cor. & $t$ & $p$ & Adjust $\mathrm{R}^{2}$ & $\mathbf{F}$ & $p$ \\
\hline & & & & & 0.12 & 26.81 & 0.000 \\
\hline NR_Self & 0.26 & 0.24 & 9.99 & $0.000^{*}$ & & & \\
\hline NR_Perspective & -0.10 & -0.08 & -3.45 & $0.001 *$ & & & \\
\hline NR_Experience & 0.26 & 0.26 & 0.72 & 0.473 & & & \\
\hline Egocentric & 0.00 & 0.00 & 0.090 & 0.931 & & & \\
\hline Altruistic & 0.09 & 0.07 & 3.12 & $0.002 *$ & & & \\
\hline Biospheric & 0.14 & 0.11 & 4.84 & $0.000 *$ & & & \\
\hline
\end{tabular}

*Significant at the alpha level

internalized identification with nature reflecting favorable feelings and thoughts about their personal connection to nature. These results were consistent with a previous research study conducted by Ozsoy and Ahi (2012), who reported that primary and middle school students portrayed humans as a part of nature since the majority of the students drew people in their pictures of "environment." This was similar to the research sampling of students from a Canadian university (Nisbet, 2005) regarding individuals being personally connected to nature. In this study, these students held prevalently nature-related world views about human treatment of animals and the use of natural resources.

While investigating the students' physical familiarity with the natural world, it was found that although they held a strong desire to spend more time outdoors, they seemed to have distinct thoughts about being in and observing "wild" natural areas. This result could be attributed to claims by Louv (2005) indicating that many children living in urban environments are not provided with opportunities to have access to nature. This author pointed out that many parents do not let their children explore wild natural areas since parents have concerns about their children's safety. Louv also stated that parents and teachers put added academic pressures on students which mean spending more time indoors, especially staying in front of computers for longer periods of time. This reduced contact with nature appeared to disrupt the feelings of the students in the current study to connect to "wild" nature and has resulted in a growing fear of wild life.

The current study revealed that the middle school students put a high emphasis on each item considering the "self," other people and all living things in terms of environmental concern. However, these students seemed to prioritize egocentric motive concerns when compared to altruistic and biospheric motive concerns. The students appreciated the environment and developed feelings of concern about environmental problems for the sake of their own interests and needs. To be more specific, they were highly concerned about current threats and risks on the environment due to adverse consequences on their own health, their future, and their children. In contrast to this study, Onur et al. (2012), who investigated motive concerns of elementary school students from a rural area in Turkey, reported that different aspects of motive concerns were very close to each other for these individuals. In other words, it appeared that these students supported environmental protection for their own benefits as well as for the sake of the ecosystem. Prevalent egoistic motive concerns of the students in current study indicated that they might experience some difficulties in connecting the dots between humans and nature. Curriculum developers, textbook authors, and teachers in science and sustainability education might consider the suggestions provided by de Groot and Steg (2009). These researchers pointed out that environmentally responsible behavior could be reinforced while hindering the controversies originated from egoism, altruism, and biospherism perspectives. For example, climate change mitigation is beneficial to their own health since climate change and greenhouse gases are accelerating pollen production for children who have seasonal allergies and asthma. From an altruistic perspective, climate change stimulates the challenge of providing adequate and safe fresh water to meet the needs of future generations. Citizens of the poorest countries are also already experiencing the effects of climate change in terms of food security. Regarding the biospheric concerns, the risks on biodiversity attract the attention while considering the consequences of climate change. Alternatively, as suggested by de Groot and Steg (2009), we as educators could make altruistic and biospheric motives more remarkable in the context of cognitive development.

The present study indicated that majority of the students were not actively involved in different levels of responsible environmental behaviors. Looking in detail, it was found out that these students were not involved in political actions such as communicating with government officials regarding the importance of environment or encouraging the government officials to create public bulletin boards to increase public support for environmental protection. On the other hand, they had a moderate tendency to be active in physical and consumer actions such as recycling, picking up litter and throwing it in garbage bins, or taking steps to conserve water. These trends reported for Turkish middle school students' environmentally responsible behaviors were consistent with a previous research study sampling Turkish pre-service science teachers (Alper, 2014). Such findings might be attributed to the claims stating that teachers are acting as role models for children so teachers should demonstrate the characteristics and behaviors that motivate individuals to become concerned and active in being responsibly environmentally committed (Chawla and 
Cushing, 2007). Furthermore, Wilson (1996) who provided some practical tips for environmental education programs for the early years, stressed a teacher should be a role model of caring and respecting the natural environment.

Regarding rarely observed political actions among Turkish middle school students, Erdoğan et al. (2012) pointed out that such kinds of action are required to be performed mostly through the guidance of non-governmental organizations. However, political actions along with persuasion actions reflecting "public sphere" (Short, 2010) increased the scope of environmental commitment and created a greater impact when compared to individual physical commitment (Hungerford et al., 2003).

\section{Predicting Middle School Students' Environmentally Responsible Behaviors}

The present study was an initial attempt to investigate the predictive power of environmental motive concerns and NR on middle school students' environmentally responsible behaviors. The findings indicated that egoistic motive concerns of these students were not among statistically significant predictors of responsible environmental behaviors. In contrast, in Sahin's study (2013), it was found out that concerns for self were significantly related to the energy conservation behaviors of teacher candidates in Turkey. In addition to Sahin's study, Nordlund and Garvill (2002) supported that egoistic individuals were less likely to conserve natural resources. Regarding the significant predictors of environmentally responsible behaviors in this study, it was revealed that the students who had higher levels of external, nature-related world view about how humans interact with other living things and showing an internalized identification with nature did report more environmentally responsible behaviors. Furthermore, when their concern about environmental deterioration was for all life and humans other than the self, they showed a higher tendency to engage in proenvironmental actions. The findings in this study are consistent with theories which suggest having nature-related world views enhance pro-environmental behaviors (e.g., Chawla, 2007; Wells and Lekies, 2006). Previous research (Gutierrez 1996; Schultz and Zelezny, 1999; Thompson and Barton, 1994)) has revealed that the individuals are having biospheric and altruistic motive concerns have a higher tendency to demonstrate pro-environmental behaviors. Nisbet et al. (2009) confirmed that nature-related emotions, values, attitudes, and a self-concept that includes the natural world as well as a biospheric orientation may provide a motivational force toward nature protection and preservation. This study provided some evidence showing that middle school students' altruistic and biospheric motive concerns had significant potential to make contributions on facilitating their environmental responsible behaviors. Therefore, outdoor activities acting on biospheric and altruistic concerns or any classroom activity emphasizing that caring for all living things contributes to life quality of our friends, other people or our children would lead to reinforce environmentally responsible behaviors through science and sustainability education.

\section{CONCLUSIONS}

Learning outcomes included in Turkish primary education programs are generally based on acquiring knowledge and understanding environmental issues, but they neglect to put on an emphasis on developing skills, values and perspectives toward nature (Tanriverdi, 2009). Jensen (2002) suggested that activity-based teaching should be held in the schools to prepare environmentally active individuals. In the teaching process, it was pointed out that teachers could take into consideration activities consisting of physical, chemical, and biological investigations of a polluted lake, thereby linking the human nature interactions from a sustainability education perspective. Jensen also proposed that these activities held a potential to encourage students' motivation and facilitate their acquisition of environmental knowledge. Kossack and Bogner (2011) conducted a 1 day education program promoting the connectedness to nature and observed that there were significant changes even in their participants' connectedness to nature 7 weeks later. Ernst and Theimer (2011) suggested that only programs with "a condensed time frame of sufficient duration" might have a favorable impact on connectedness. Schultz (2002) also suggested that a sense of being in nature is associated with how the individual place herself/himself in nature, and so how he or she may change their behaviors toward nature, take some responsibilities to protect it. From this perspective, the present study encourages educators, curriculum developers, and textbook authors to touch on children's environmental identity reflected by nature connectedness and values. Such an approach has a significant potential to create a sustainable future for the next generations.

\section{REFERENCES}

Alper, U. (2014). Modelling Pre-Service Science Teachers' Environmentally Friendly Behaviours in Relation to Psychological and Cognitive Variables. Unpublished PhD Dissertation. Middle East Technical University, Ankara, Turkey.

Barthelmess, P.Y., Schüz, M., Fuchs, R., Kučera, D., \& Prandini, M. (2013). Different shades of green: A comparative study on nature relatedness and ecological consciousness among South Korean, Swiss, and Czech students. Central European Business Review, 2(2), 7-18.

Cakir, B., Karaarslan, G., Sahin, E., \& Ertepinar, H. (2015). Adaptation of nature relatedness scale to Turkish. Elementary Education Online, 14(4), 1370-1383.

Carter, L. (2012). Globalization and science education: Global information culture, post-colonialism and sustainability. In: Fraser, B.J., \& Tobin, K.G., (Eds.), Second International Handbook of Science Education. New York: Springer. pp. 899-912.

Chawla, L. (2007). Childhood experiences associated with care for the natural world: A theoretical framework for empirical results. Children, Youth and Environments, 17, 144-170.

Chawla, L., \& Cushing, D.F. (2007). Education for strategic environmental behavior. Environmental Education Research, 13, 437-452.

de Groot, J.I.M., \& Steg, L. (2009). Mean or green: Which values can promote stable pro-environmental behavior? Conversation Letters, 2, 61-66.

Dietz, T., Kalof, L., \& Stern, P.C. (2002). Gender, values, and environmentalism. Social Science Quarterly, 83, 353-364.

Erdoğan, M., Ok, A., \& Marcinkowski, T.J. (2012). Development and validation of children's responsible environmental behavior scale. Environmental Education Research, 4, 507-540. 
Ernst, J., \& Theimer, S. (2011). Evaluating the effects of environmental education programming on connectedness to nature. Environmental Education Research, 17(5), 577-598.

Feral, C.H. (1998). The connectedness model and optimal development: Is eco-psychology the answer to emotional well-being? The Humanistic Psychologist, 26, 243-274.

Field, W.A. (2005). Discovering Statistics Using SPSS. $2^{\text {nd }}$ ed. London: Sage.

Gutierrez, K.D. (1996). Values and their effect on pro-environmental behavior. Environment and Behavior, 28(1), 111-133.

Higgins, P., \& Kirk, G. (2006). Sustainability education in Scotland: The impact of national and international initiative on teacher education. Journal of Geography in Higher Education, 30(2), 313-326.

Hungerford, H., Litherland, R., Peyton, R., Ramsey, J., \& Volk, T. (2003). Investigating and Evaluating Environmental Issues and Actions Skill Development Modules. Champaign, IL: Stipes Publishing Co.

Jensen, B.B. (2002). Knowledge, action and pro-environmental behaviour. Environmental Education Research, 8(3), 325-334.

Kaplan, S. (2000). Human nature and environmentally responsible behavior. Journal Social Issues, 56, 491-508.

Kossack, A., \& Bogner, F. (2012). How does a one-day environmental education programme support individual connectedness with nature? Journal of Biology Education, 48(3), 180-187.

Louv, R. (2005). Last Child in the Woods. Chapel Hill, NC: Algonquin Books.

Maller, C., Townsend, M., Pryor, A., Brown, P., \& Leger, L. (2005). Healthy nature healthy people: 'Contact with nature' as an upstream health promotion intervention for populations. Health Promotion International, 21, 45-54.

Milfont, T.L., Duckitt, J., \& Cameron, L.D. (2006). A cross-cultural study of environmental motive concerns and their implications for proenvironmental behavior. Environment and Behavior, 38, 745-767.

Nisbet, E.K.L. (2005). Increasing Nature Relatedness, Environmental Concern, and Well-Being Through Education, Master's Thesis. Carleton, Canada: Carleton University.

Nisbet, E.K., \& Zelenski, J.M. (2013). The NR-6: A new brief measure of nature relatedness. Frontiers in Psychology, 4, 813.

Nisbet, E.K.L., Zelenski, J.M., \& Murphy, S.A. (2009). The nature relatedness scale: Linking individuals' connection with nature to environmental concern and behavior. Environment and Behavior, 41, 715-740.

Nordlund, A., \& Garvill, J. (2002). Value structures behind pro-environmental behavior. Environment and Behavior, 34, 740-756.

Onur, A., Şahin, E., \& Tekkaya, C. (2012). An investigation on value orientations, attitudes and concern towards the environment: The case of Turkish elementary school students. Environmental Education Research, 18(2), 271-297.

Orr, D.W. (2004). Earth in Mind: On Education, Environment, and the Human Prospect. Washington, DC: Earth Island Press.

Ozsoy, S., \& Ahi, B. (2014). Öğrencilerinin geleceğe yönelik çevre algilarinin çizdikleri resimler araciliği ile belirlenmesi. Kuram ve Uygulamada
Eğitim Bilimleri, Educational Sciences: Theory and Practice, 14(4), 1557-1582.

Sahin, E. (2013). Predictors of Turkish elementary teacher candidates' energy conservation behaviors: An approach on value-belief-norm theory. International Journal of Environmental and Science Education, 2, 269-283.

Schmuck, P. (2003). Biospheric, Altruistic, Egoistic Environmental Concern and Environmental Behavior. Paper Presented at the $5^{\text {th }}$ Biannual Meeting of the Division of Environmental Psychology of the German Psychological Association, Eindhoven, Netherlands.

Schultz, P.W. (2000). Empathizing with nature. Journal of Social Issues, 56(3), 391-406.

Schultz, P.W. (2001). The structure of environmental concern: Concern for self, other people, and the biosphere. Journal of Environmental Psychology, 21, 327-339.

Schultz, P.W. (2002). Inclusion with nature. In: Scmuck, P., \& Schultz, P.W., (Eds.), Psychology of Sustainable Development. Boston: Kluwer Academic Publishers.. .

Schultz, P.W., Shriver, C., Tabanico, J., \& Khazian, A. (2004). Implicit connections with nature. Journal of Environmental Psychology, 24, 31-42.

Schultz, P.W., \& Zelezny, L. (1999). Values as predictors of environmental attitudes: Evidence for consistency across 14 countries. Journal of Environmental Psychology, 28, 255-265.

Short, P.C. (2010). Responsible environmental action: Its role and status in environmental education and environmental quality. Journal of Environmental Education, 41(1), 7-21.

Smithson, M.J. (2003). Confidence Intervals, Quantitative Applications in the Social Sciences Series, No. 140. Thousand Oaks, CA: Sage.

Steg, L., Dreijerink, L., \& Abrahamse, W. (2005). Factors influencing the acceptability of energy policies: A test of VBN theory. Journal of Environmental Psychology, 25, 415-425.

Stern, P.C., \& Dietz, T. (1994). The value basis of environmental concern. The Journal of Social Issues, 50(3), 65-84.

Tanrıverdi, B. (2009). Sürdürülebilir çevre eğitimi açisindan ilköğretim programlarinin değerlendirilmesi. Kocaeli Üniversitesi Eğitim ve Bilim Dergisi, 151(34), 89-103.

Thompson, S.C.G., \& Barton, M.A. (1994). Ecocentric and anthropocentric attitudes toward the environment. Journal of Environmental Psychology, $14,149-157$

U.S. Environmental Protection Agency. (2012). U.S. Environmental Protection Agency Scientific Integrity Policies. Available from: https:// www.epa.gov/sites/production/files/2014-02/documents/scientific integrity policy 2012.pdf. [Last accessed on 2017 Jun 22].

Wilson, R.A. (1996). Starting Early: Environmental Education During the Early Childhood Years. Available from: https://www.ericdigests. org/1998-1/early.htm(ED402147). [Last accessed on 2017 Jun 19]

Wells, N., \& Lekies, K. (2006). Nature and the life course: Pathways from childhood nature experiences to adult environmentalism. Children, Youth and Environments, 16, 1-24. 